\title{
Spatial differentiation of comprehensive suitability sustainable development for urban human settlements based on GISØA case study of Liaoning Province, China
}

\section{Yingying Guan (D GYY9418@126.com )}

Liaoning Normal University https://orcid.org/0000-0003-1175-3342

\section{Xueming Li}

Human Settlements Research Center, Liaoning Normal University, 116029 Dalian, China

\section{Songbo Li}

Human Settlements Research Center, Liaoning Normal Universsity, 116029 Dalian, China

Shenzhen Tian

Human Settlements Research University, 116029 Dalian, China

\section{Research Article}

Keywords: Human settlements comprehensive suitability index ( $\mathrm{HSCl})$, Natural suitability, Humanistic suitability, Spatial differentiation, Sustainable development

Posted Date: March 5th, 2021

DOl: https://doi.org/10.21203/rs.3.rs-292928/v1

License: (c) (i) This work is licensed under a Creative Commons Attribution 4.0 International License. Read Full License 


\section{Abstract}

The comprehensive suitability of regional human settlements is of great significance to the development and spatial distribution of regional human settlements and regional social and economic development. In this study, based on the traditional evaluation of the natural suitability of the human settlements, this study adds humanistic indicators to comprehensively evaluate the suitability of the human settlements in Liaoning, China. In particular, we sought to uncover the spatial differentiation law of the comprehensive suitability of these settlements and its correlations with population density and GDP density, provide a theoretical basis for urban human settlements planning and governance. The main conclusions were as follows: (1) the natural suitability index in Liaoning Province presents the law of longitudinal spatial differentiation from northeast to southwest, which follows the direction of the mountains; (2) the highest to lowest humanistic suitability indexes were as follows: the central, eastern, and western regions; (3) the highest to lowest spatial differentiations of the comprehensive suitability of the human settlements were as follows: the central and coastal, eastern, and western regions;(4) the spatial distribution of population-economy density in Liaoning Province was basically consistent with the spatial distribution of the comprehensive suitability index of human settlements, The population economy is concentrated in the areas with the best and moderate human settlements. Ultimately, we found that the distributions of population-economy and human settlement suitability were relatively coordinated and that highly suitable land was already fully utilized.

\section{Introduction}

A human settlement is a multi-disciplinary and multi-level surface space system closely connected to human activities(Li et al., 2012). As spaces where human beings live, human settlements are the geographic bases for humans to engage in productive life activities; accordingly, settlements have long attracted widespread attention from geographers, ecosystem scholars, and sociologists(Yang et al., 2018; Sarı et al., 2020; Pourebrahim et al., 2011). Today, the acceleration of urbanization has prompted domestic and foreign scholars to increasingly focus on what makes a human settlement suitable for a good life(Li et al., 2018; Li et al., 2017). The expansion of this field of research has brought with it numerous new applications and increasing interdisciplinary coordination(Chavez-Rosales et al., 2019; Wang et al., 2019).

The spatial layout and development any particular human settlement are constituted by that settlement's unique natural conditions and the subjective initiatives of its founders and inhabitants. Existing research on human settlements mainly explore five major systems-namely, the natural ecological environment(Cui et al., 2018; Qiu et al., 2019), human culture(Ahamed et al., 2020), social economy(Cui et al., 2018; Yang et al., 2020), living conditions, and architectural supports(Nouri et al., 2017)-and zoom in on select areas with specific development conditions(Wei et al., 2013; Jiao et al., 2012; Bathrellos et al., 2013), such as special geographical environment regions(Alatawi et al., 2020; Milanesi et al., 2015; Buruso, 2018), natural regions subject to environmental protections, agricultural and animal husbandry cities(Weisong et al., 2019; Sarı et al., 2020), mining cities, and riverside cities or cities located by a lake 
basin(Casarotto et al., 2019; Chavez-Rosales et al., 2019; Nouri et al., 2017). The spatial scale of this research extends across global, regional, urban, community(Wei et al., 2020), and architectural levels(Jin et al., 2016; Wei et al., 2020; Hou et al., 2016). Meanwhile, such suitability research uses theoretical models from geography, ecology, environmental studies, and economics(Li et al., 2019); established index and model systems; and software such as ArcGIS10.2 and ENVI5.0 to spatially visualize settlements, quantitatively analyze the evolution of suitability across time and space(Luo et al., 2019), and simulate and predict the future development of human settlements(Milanesi et al., 2015). Notably, suitability research has become a new entry point for urban settlement research with the deepening of urbanization, which has seen the gradual transformation of urban industries, land use structures(Pearson, 2020; Luo et al., 2019), and natural and social environments(Xiao et al., 2019; Ge et al., 2020; Li et al., 2011). Generally, this line of scholarship seeks to comprehensively understand the natural and humanistic elements involved in the development of urban settlements, evaluate the comprehensive suitability of urban settlements, provide theoretical support and a basis for research into the sustainable development of sustainable development for urban settlements, maximize resource utilization efficiency, and optimize settlement layouts.

With economic development and urbanization continuing to progress in China, cities are also facing problems related to the development of human settlements, such as issues related to population agglomeration, industrial structure transformation, and land use structure transformation(Xiao et al., 2018; Li et al., 2011; Zheng et al., 2019). Analyzing the comprehensive suitability of sustainable development for urban settlements is conducive to their sustainable, scientific, and reasonable development. At present, most studies on the suitability of urban human settlements limit their spatial scales to the city rather than the province(Xiao et al., 2019; Weisong et al., 2019; Ge et al., 2020), use basic research methods such as statistical counting and spatial analysis, use a natural suitability perspective, and focus primarily on the integration of humanistic and natural elements.

To offer insights on suitability at a provincial scale, this study explored the case of Liaoning Province. In particular, we unpacked the impact of select natural elements on suitability, such as the relief degree of land surface (RDLS) index(Xiao et al., 2018b; Milanesi et al., 2015), the normalized difference vegetation index (NDVI)(Hou et al., 2016), the hydrology index (HI), the temperature and humidity index (THI)(Shao et al., 2020; Nouri et al., 2017), the land cover index (LCI)(Bikdeli, 2020; Wei et al., 2020; Shao et al., 2020), the nighttime light index (NLI), the land traffic accessibility index (LTAI), the air quality index (AQI) and other humanistic elements. Notably, we synthesized natural and humanistic suitability indicators to establish a comprehensive suitability index evaluation model for settlements based on the work we performed with ArcGIS10.2, ENVI5.0, spatial quantitative analysis, and our evaluation of the comprehensive suitability of sustainable development for settlements in Liaoning. Ultimately, we hope to provide a new research perspective for research on the comprehensive suitability of sustainable development for settlements in Liaoning Province.

\section{Materials And Methods}




\subsection{Study area}

Our study area was Liaoning Province $\left(38^{\circ} 43^{\prime} \varangle 43^{\circ} 26^{\prime} \mathrm{N} \otimes 118^{\circ} 53^{\prime} \otimes 125^{\circ} 46^{\prime} \mathrm{E}\right)$, which is located in the southern region of Northeast China and borders the Yellow Sea and the Bohai Sea to the south, Hebei Province to the southwest, the Inner Mongolia Autonomous Region to the northwest, and Jilin Province to the northeast. Liaoning has a temperate continental climate. The terrain of Liaoning, which extends across $148,000 \mathrm{~km}^{2}$, slopes from the east to west, descending into a central plain that leans toward the Bohai Sea in a horseshoe shape. Liaoning is the only coastal and border province in Northeast China as well as the gateway to Northeast China and the eastern region of the Inner Mongolia Autonomous Region.

\subsection{Index selection and model creation}

Human settlements are complex. In order to systematically evaluate the comprehensive suitability of sustainable development for settlements in Liaoning, we established an evaluation model of natural elements, including topography, climate, hydrology, and vegetation coverage and an evaluation model of humanistic elements, including land use index, night light index, traffic accessibility, and air quality conditions. Using ArcGIS10.2 and ENVI5.0, with a $100 \mathrm{~m} \times 100 \mathrm{~m}$ grid as the basic research unit, we calculated the comprehensive suitability index and the related spatial distribution of sustainable development for the settlements in Liaoning (Fig 2).

\subsubsection{Natural element indicator selection}

The natural elements of a region are undoubtedly related to sustainable development for human settlements. Natural elements are the objective conditions that limit regional settlements and are not easy to change by human will. Along these same lines, terrain conditions directly or indirectly affect settlement site selection and development as well as the pros and cons of land use and quality. It is important to note here that the basic natural system conditions that support the development of settlements include terrain, vegetation coverage, hydrology, and climate.

In order to establish Liaoning's topographic features and their impact on sustainable development for human settlements, we used the RDLS index model proposed by Feng Zhiming and Wei Wei to calculate the RDLS index(Li et al., 2019)(Fig 3a). Meanwhile, because the normalized difference vegetation index (NDVI) can accurately reflect the characteristics of vegetation in a settlement, we adopted the NDVI model to reflect the vegetation coverage in Liaoning (Fig $3 b$ ). The vegetation coverage index can characterize the regional distribution of natural elements directly related to the sustainable development of human settlements, such as groundwater, surface water, and soil fertility(Bikdeli, 2020); changes in temperature and humidity growth trends; industrial and agricultural production; and daily life. Moreover, the vegetation coverage index plays an important role in supporting the settlements and economic and social development in the region. In step with China's ecological environment evaluation standards., we used the proportion of water area and precipitation to characterize the scarcity of water resources in the study area 
(water area reflects the capacity of water collection in the region and precipitation reflects the natural water supply capacity of the region under natural conditions). Also notable here is that the amount of water resources directly affects the water content of soil. We used the hydrology index $(\mathrm{HI})$ model proposed by Feng Zhiming(Sun et al., 2018) to calculate the hydrology index distribution (Fig 3c). Meanwhile, the temperature and humidity index evaluates the comfort of the human body under various climatic and environmental conditions from the perspective of meteorology. We used the temperature and humidity index model to evaluate the climate suitability model of the study area (Fig 3d). Ultimately, then, we selected the RDLS index, NDVI, hydrology index, and the temperature and humidity index to synthesize a model for evaluating the suitability of Liaoning's natural environment for settlements. Based on the quantitative evaluation of the above single element of natural suitability, we established an evaluation model of the natural suitability of settlements (Table 1).

\subsubsection{Humanistic element indicator selection}

Humanistic factors are transformative forces that result from human activities and can therefore reflect the subjective initiatives behind human changes to settlements. Land use conditions, urban construction land agglomeration, the accessibility of traffic, and air quality all reflect the important role of human activities in the development and evolution of settlements. Therefore, we selected the land cover index, NLI, LTAI and AQI to comprehensively evaluate the suitability of Liaoning's existing settlements for human life.

The land coverage index comprehensively reflects the land use mode and land cover situation in the region, and the land use type and NDVI were used to characterize the suitability of land coverage and reflect the surface coverage of the study area by constructing a land cover index model (Fig 4a). The NLI can characterize the intensity of human activities, is widely used to identify urban construction land, has a high correlation with the level of urbanization, and is an important indicator of the humanistic character of an urban settlement. The DMSP/OLS sensor, which comprises the Operational Linescan System (OLS) mounted on the United States' Defense Meteorological Satellite Program (DMSP), works at night and uses visible light-near infrared bands to retrieve NLI and gray value; the range is 0 63(Yang et al., 2016) (Fig 4b). Additionally, traffic accessibility characterizes the convenience of population and goods circulation, and is an important indicator for evaluating the degree of aggregation and circulation in a settlement. The indicators used to evaluate traffic accessibility mainly included the distance method, opportunity accessibility, economic potential model, topological accessibility, and weighted average travel time; meanwhile, the calculation methods mainly included the network analysis method and the costdistance weighted analysis method(Jiao et al., 2020). By situating 14 prefecture-level cities in Liaoning Province as spatial nodes, setting weighted average travel time as the measurement index, and employing ArcGIS10.2, we used a cost-distance weighted analysis to evaluate each node's land traffic accessibility based on 2015 economic, population, and traffic data (Fig 4c). It is helpful to note here that air pollution, which is the result of settlement activities, significantly affects the quality of settlements. Liaoning in particular is an important industrial province, and thus the air pollution caused by industrial production in the province has certainly impacted the development of its settlements. Of particular note is 
that when atmospheric pollutants such as PM2.5 and PM10 enter the human body, they can cause respiratory diseases (e.g., lung cancer) and heart disease, thereby directly affecting the safety of human life. We used the AQI to quantitatively measure Liaoning's air pollution (Fig 4d). Based on this quantitative evaluation of humanistic suitability, we established a humanistic suitability of sustainable development for human settlements evaluation model (Table 2).

Table 3 Weights of landuse types

\begin{tabular}{|c|c|c|c|c|c|c|c|}
\hline $\begin{array}{c}\text { First-level } \\
\text { classification }\end{array}$ & Weight & $\begin{array}{l}\text { Second-level } \\
\text { classification }\end{array}$ & Weight & $\begin{array}{c}\text { First-level } \\
\text { classification }\end{array}$ & Weight & $\begin{array}{l}\text { Second-level } \\
\text { classification }\end{array}$ & Weight \\
\hline \multirow{4}{*}{$\begin{array}{c}\text { Garden } \\
\text { forestland }\end{array}$} & 0.18 & Closed forestland & 0.33 & \multirow{3}{*}{$\begin{array}{c}\text { Water } \\
\text { area,wetland }\end{array}$} & \multirow[t]{3}{*}{0.14} & Rivers, lakes & 0.40 \\
\hline & & Shrub land & 0.27 & & & Reservoir,swag & 0.35 \\
\hline & & Sparse forestland & 0.21 & & & $\begin{array}{c}\text { Tidal-flat } \\
\text { area,wetland }\end{array}$ & 0.25 \\
\hline & \multirow{4}{*}{0.29} & Other forestland & 0.19 & \multirow[t]{3}{*}{ Construction land } & \multirow[t]{3}{*}{0.10} & Urban land & 0.49 \\
\hline \multirow[t]{3}{*}{ Grassland } & & Height cover grass & 0.40 & & & $\begin{array}{l}\text { Rural residential } \\
\text { land }\end{array}$ & 0.29 \\
\hline & & Medium cover grass & 0.39 & & & $\begin{array}{c}\text { Other construction } \\
\text { land }\end{array}$ & 0.22 \\
\hline & & Low cover grass & 0.21 & \multirow[t]{3}{*}{ Unused land } & \multirow[t]{3}{*}{0.07} & Bare land & 0.29 \\
\hline \multirow[t]{2}{*}{ Arable land } & 0.22 & Irrigated cropland & 0.40 & & & Bare rock gravel & 0.24 \\
\hline & & Dry land & 0.60 & & & Other unused land & 0.47 \\
\hline
\end{tabular}

\subsubsection{Model to evaluate the comprehensive suitability of human settlements}

Existing research on best practices for evaluating the suitability of sustainable development for settlements mostly uses the correlation coefficients between the elements of human settlements, with the population as the weight of each element(Saatsaz et al., 2018; Ustaoglu and Aydınoglu, 2020). The analytic hierarchy process, expert scoring method, entropy weight method, element analysis method, and principal component analysis method are commonly used to determine the weight of each element of a settlement(Maimaiti et al., 2017; Jiao et al., 2020). This study combined the analytic hierarchy process and expert scoring method to determine the weight of each element (Table 4).

Table 4 Weights of human settlements indicator

\begin{tabular}{lccc}
\hline Evaluation elements & Single factor index & Single element weight & Comprehensive weight \\
\hline Natural element & Relief degree of land surface index & 0.287 & 0.143 \\
& Normalized difference vegetation index & 0.329 & 0.165 \\
\cline { 2 - 4 } & Hydrology index & 0.178 & 0.089 \\
\cline { 2 - 4 } humanistic element & Temperature and humidity index & 0.206 & 0.103 \\
\cline { 2 - 4 } & Land cover index & 0.291 & 0.136 \\
\cline { 2 - 4 } & Nighttime light index & 0.285 & 0.184 \\
\cline { 2 - 4 } & Land traffic accessibility index & 0.163 & 0.081 \\
\hline
\end{tabular}

After processing the range standardizations of each single element index, we calculated the natural element index, the humanistic element index, and the comprehensive suitability index of Liaoning's settlements. The calculation formula was as follows: 
where $\mathrm{HSCl}$ is comprehensive suitability index for human settlements; $\mathrm{HEl}$ is natural element index; NRDLS, NNDVI, NWRI, and NTHI respectively represent the normalized RDLS index, normalized difference vegetation index, hydrology index, and temperature and humidity index; $\hat{\sigma}^{\prime}, \beta^{\prime}, \chi^{\prime}$, and $\delta^{\prime}$ respectively represent the single element weights corresponding to the four indexes (Table 4); $\varepsilon^{\prime}, \theta^{\prime}, \phi^{\prime}$ and $\varphi^{\prime}$ is the humanistic element index; NLCI, NNDMSP, NLTAI, and NAQI respectively represent the normalized land cover index, nighttime light index, land traffic accessibility index, and air quality index; $\varepsilon^{\prime}, \theta^{\prime}, \phi^{\prime}, \varphi^{\prime}$ represent the single element weights corresponding to the four indexes (Table 4); and HSCl represents the comprehensive suitability index of the settlements combined with the corresponding comprehensive element weights of each index. We used ArcGIS10.2's raster calculator to obtain the comprehensive suitability index of the human settlements, $\mathrm{HSCl}$.

\subsection{Data collection and processing}

Based on natural environmental data, humanistic environmental data, social economy data, and basic geographic data (Table 5), we used ArcGIS10.2 and ENVI5.0 to perform data spatial correction, projection conversion, and raster calculation to quantitatively calculate the comprehensive suitability index of the settlements and spatially visualize them.

Table 5 Data sources

\begin{tabular}{|c|c|c|}
\hline Data types & Data names & Data sources \\
\hline \multirow{4}{*}{$\begin{array}{l}\text { Natural } \\
\text { environment } \\
\text { data }\end{array}$} & DEM data (resolution 90m) & $\begin{array}{l}\text { Documents Geospatial Data Cloud } \\
\text { [http://www.gsclound.cn/ } \square\end{array}$ \\
\hline & $\begin{array}{l}\text { MODIS data vegetation index digital image } 4 \text { MYD13Q10 } \\
250 \text { m vegetation index } 16 \text { days synthetic product }\end{array}$ & $\begin{array}{l}\text { Documents Geospatial Data Cloud } \\
\text { [http://www.gsclound.cn/[ }\end{array}$ \\
\hline & Hydrology distribution vector data & $\begin{array}{l}\text { Institute of Geographic Sciences and Natural } \\
\text { Resources Research, CAS } \square \text { http://www.igsnrr.cas.cn/ } \square\end{array}$ \\
\hline & Meteorological data,2017 & $\begin{array}{l}\text { National Weather Information Center } \\
\text { [http://data.cma.cn/ }\end{array}$ \\
\hline \multirow{4}{*}{$\begin{array}{l}\text { humanistic } \\
\text { Environmental } \\
\text { Data }\end{array}$} & Liaoning 2018 land use data $\square 100 \mathrm{~m} \times 100 \mathrm{~m} \square$ & $\begin{array}{l}\text { National Earth System Science Data Center } \\
\text { [http://loess.geodata.cn/ } \square\end{array}$ \\
\hline & $\begin{array}{l}\text { DMSOP/OLS Nighttime Light index,2013■resolution } \\
0.00833^{\circ} \text {. }\end{array}$ & $\begin{array}{l}\text { Institute of Geographic Sciences and Natural } \\
\text { Resources Research, CAS } ₫ \text { http://www.igsnrr.cas.cn/ } \square\end{array}$ \\
\hline & Liaoning 2015 vector data of land traffic & $\begin{array}{l}\text { Institute of Geographic Sciences and Natural } \\
\text { Resources Research, CAS } \square \text { http://www.igsnrr.cas.cn/ } \square\end{array}$ \\
\hline & $\begin{array}{l}\text { Liaoning } 2014 \text { air quality monitor data of } 14 \\
\text { prefecture-level cities }\end{array}$ & $\begin{array}{l}\text { Information Center of Ministry of Ecology and } \\
\text { Environment } 1 \text { http://www.mee.gov.cn/ }[\end{array}$ \\
\hline \multirow[t]{2}{*}{$\begin{array}{l}\text { social economy } \\
\text { data }\end{array}$} & Liaoning 2018 demographic data & $\begin{array}{l}\text { Liaoning } 2018 \text { statistical yearbook } \\
\text { [https://www.yearbookchina.com/ }\end{array}$ \\
\hline & Liaoning 2018 GDP statistics data & $\begin{array}{l}\text { Liaoning } 2018 \text { statistical yearbook } \\
\text { [https://www.yearbookchina.com/[ }\end{array}$ \\
\hline \multirow{2}{*}{$\begin{array}{l}\text { basic } \\
\text { geographic } \\
\text { data }\end{array}$} & County vector layer & $\begin{array}{l}\text { National Earth System Science Data Center } \\
\text { [http://loess.geodata.cn/ } \square\end{array}$ \\
\hline & Residential area layer & $\begin{array}{l}\text { National Earth System Science Data Center } \\
\text { [http://loess.geodata.cn/ } \square\end{array}$ \\
\hline
\end{tabular}

\section{Results}




\subsection{Analysis of spatial differentiation of the natural suitability of human settlements}

\subsubsection{Analysis of spatial differentiation of the natural element single element index}

This section considers the spatial distribution of the four natural suitability single element indices of the settlements in Liaoning Province. The topography undulations are high in the east and west and low in the central plain (Fig 3a). The central region of Liaoning Province comprises the flat Liao River Plain; meanwhile, the eastern mountain range is part of the of the Changbai Mountains and is home to the highest point in Liaoning-the highest relief degree of the land surface index was 0.286 in this eastern region. The western mountains stretch across the Inner Mongolia Plateau to the Liao River Plain. Notably, Shenyang and Anshan had the lowest average relief degree according to the land surface index, while Benxi and Dandong had the highest average relief degree according to the land surface index. The normalized difference vegetation index was higher in the east and west regions and lower in the central and coastal regions (Fig $3 \mathrm{~b}$ ). The lowest normalized difference vegetation index was in Shenyang and Dalian at 0.04 and the highest in Fushun, Benxi, and Dandong at 0.92. Meanwhile, the HI revealed that the western and central regions had lower distributions and the eastern region a higher distribution-this distribution gradually decreases as we moved from east to west (Fig 3c). The lowest HI was in Dalian at 0.125 and the highest in Benxi at 0.168 . Last, the temperature and humidity index was relatively low in the northwest and central regions and relatively high in the eastern and coastal regions (Fig 3d); it was lowest in Chaoyang at 0.182 and highest in Dandong at 0.275 .

\subsubsection{Analysis of spatial differentiation of natural element composite index}

We recorded the highest values for the spatial distribution of the natural element comprehensive index (Fig 4a) in Liaoning's central and coastal regions and the lowest values in the eastern and western hilly regions. The highest natural element comprehensive index was in Shenyang, Yingkou, and Dalian at 0.6008 and the lowest natural element comprehensive index in Benxi, Fushun, and Chaoyang at 0.182. The natural suitability of Liaoning's settlements were significantly affected by undulations in the terrain and the distance to the sea: the flatter the terrain, the more advantageous the layout and development of the sustainable development for human settlements; meanwhile, proximity to the sea and thus to a more humid ocean climate enhanced human comfort. Accordingly, Liaoning's central region-home to naturally suitable plains and coasts-offered better living conditions than its mountainous and hilly regions in the west and east.

\subsection{Analysis of spatial differentiation of the humanistic suitability of human settlements}

\subsubsection{Analysis of spatial differentiation of humanistic element single element index}


We now turn to the spatial distribution of the four humanistic suitability single element indices of Liaoning's settlements. The spatial distribution of the land cover index reveals the highest values in Liaoning's central and coastal regions and lowest values in the eastern and western regions (Fig $5 \mathrm{a}$ ); the highest index was 0.96 in Shenyang and Tieling City, and the lowest was 0.03 in Chaoyang. The spatial difference of the NLI offered an obvious finding: Urban regions had a higher index and non-urban regions had a lower one, and urban regions were agglomerated and connected (Fig 5b)-the highest average NLI was in Shenyang at 63. The LTAI revealed a circular distribution, with Shenyang, Huludao, and Dalian at the center, and a gradually decreasing trend from this multi-center connection in an east-west direction (Fig 5c)-the highest value was 1.5-2 $\mathrm{h}$ in Shenyang, Huludao, and Dalian and the lowest was 4.5-5 $\mathrm{h}$ in Chaoyang. Meanwhile, the AQI revealed obvious spatial differences, gradually decreasing from the central plan out to both the east and west. The highest AQI was in Shenyang at 136 and the lowest in Benxi at 74 .

\subsubsection{Analysis of spatial differentiation of humanistic element composite index}

The spatial distribution of the humanistic element composite index (Fig 4b) showed that the central region had the highest value and the eastern region a higher value than the western region. The relatively flat terrain of Liaoning's central region is conducive to land use and development, dense and convenient traffic networks, urban population agglomeration, and the fast development of industry and agriculture; accordingly, the humanistic element composite index of the suitability of settlements in this region was relatively high. Meanwhile, Liaoning's eastern and western regions are restricted by natural elements such as their topographies and thus the degree of land use was less disturbed by human activities and the air quality better; however, along these same lines, options for land transportation were not as convenient as in the central and coastal regions and accordingly the humanistic element composite index was low. Notably, the highest index was in Shenyang, Huludao, and Dalian at 0.83 and the lowest index in Chaoyang at 0.28 .

\subsection{Analysis of spatial differentiation of comprehensive suitability index of human settlements}

The spatial distribution of the comprehensive suitability index of the sustainable development for human settlements in Liaoning (Fig $4 \mathrm{C}$ and Table 6 ) was distributed across the mountainous terrain on the east and west sides; the middle region was high and the east and west regions were relatively low longitudinally; meanwhile, the circular distributions along Bohai Bay and the Yellow Sea's coast were better than those in inland regions, the spatial distribution characteristics of the combination of longitudinal and circular. The central and coastal regions had flat terrains, mild climates, convenient transportation networks, and rapidly developing population resources and thus high comprehensive suitability for settlements; meanwhile, the eastern and western regions were home to mountainous and hilly terrains, urban development, industrial layouts, and infrastructure construction, which were all restricted by the natural environment, and thus the comprehensive suitability indexes of settlements in 
these regions were relatively low. The highest comprehensive suitability index was in Shenyang and Dalian at 0.749 , and the lowest in Chaoyang and Fushun at 0.17.

Table 6 comprehensive suitability average index of human settlements of each city in Liaoning Province

\begin{tabular}{ccccc}
\hline City & $\begin{array}{c}\text { comprehensive suitability index of } \\
\text { sustainable development for } \\
\text { human settlements }\end{array}$ & City & $\begin{array}{c}\text { comprehensive suitability index } \\
\text { of the sustainable development } \\
\text { for human settlements }\end{array}$ & $\begin{array}{c}\text { City } \\
\text { comprehensive } \\
\text { suitability index } \\
\text { of sustainable } \\
\text { development for } \\
\text { human } \\
\text { settlements }\end{array}$ \\
\hline Shenyang & 0.749 & Dandong & 0.284 & 0.703 \\
Dalian & 0.653 & Panjin & 0.643 & 0.314 \\
Anshan & 0.671 & Yingkou & 0.657 & 0.564 \\
Fushun & 0.704 & Fuxin & 0.501 & Tieling \\
Benxi & 0.262 & Liaoyang & 0.513 & Hinghou \\
\hline
\end{tabular}

\subsection{Correlation between comprehensive suitability index of human settlements and population-economic distribution}

The spatial distributions of Liaoning's population and GDP densities were quite similar to the spatial distributions of its comprehensive suitability indexes for settlements; that is, these distributions were higher in Liaoning's central region and lower in its eastern and western regions, with Shenyang and Dalian at the center of our spatial collection. The single element index and the comprehensive suitability index of settlements suitability demonstrated high correlations with population and GDP densities (Table 7). The RDLS index and the NDVI were found to be negatively correlated with the spatial distribution of population and GDP densities, and other indexes were positively correlated. The NLI had the highest correlation with the spatial distributions of population and GDP densities at 0.193 and 0.174 , respectively; meanwhile, the $\mathrm{HI}$ had the lowest correlation with the spatial distributions of population and GDP densities at 0.063 and 0.041 , respectively. Therefore, the comprehensive suitability of Liaoning's settlements was basically consistent with the spatial distribution pattern of population and GDP densities, with Liaoning's population and economy generally distributed in regions with comprehensive suitability indexes between 0.31 and 0.74 .

Table 7 Correlation coefficient between human settlements indices and population density,GDP density

\begin{tabular}{ccc}
\hline Evaluation elements & $\begin{array}{c}\text { Correlation coefficient with population } \\
\text { density }\end{array}$ & $\begin{array}{c}\text { Correlation coefficient with GDP } \\
\text { density }\end{array}$ \\
\hline $\begin{array}{c}\text { Relief degree of land surface index } \\
\text { Normalized difference vegetation index }\end{array}$ & $-0.124^{* *}$ & $-0.136^{* *}$ \\
Hydrology index & $-0.082^{* *}$ & $0.141^{* *}$ \\
\hline Temperature and humidity index & $0.063^{* *}$ & $0.041^{* *}$ \\
\hline Land cover index & $0.071^{* *}$ & $0.053^{* *}$ \\
\hline Nighttime light index & $0.174^{* *}$ & $0.155^{* *}$ \\
\hline Land traffic accessibility index & $0.193^{* *}$ & $0.174^{* *}$ \\
\hline Air quality index & $0.106^{* *}$ & $0.169^{* *}$ \\
\hline settlements & $0.187^{* *}$ & $0.172^{* *}$ \\
\hline
\end{tabular}


Although the spatial distributions of the population-economic distribution and the comprehensive suitability index were similar, they were not completely consistent. In order to accurately reflect the correlation between the comprehensive suitability of these distributions, we took the comprehensive suitability index as the abscissa and drew the curves of the cumulative percentages of population, GDP, and land area (Fig. 7). The slope of the cumulative curve in a certain interval reflects the economic quantity of the population in the interval. The cumulative percentages of population, GDP, and land area all emerged as " $\mathrm{s}$ " curves with similar trends; however, they were not completely coincident. When HSCl was between 0.17 and 0.4 , The cumulative percentage of population and GDP is smaller than that of land, and the slope difference is small. In this case, Liaoning's land can carry economic and population concentration, and about $18 \%$ of the population live in these areas, with approximately $12 \%$ of the population presenting in these areas. When the $\mathrm{HSCl}$ was between 0.42 and 0.59 , the cumulative percentages of population and GDP were less than the cumulative percentage of land. In such cases, land was in an unsaturated state, with approximately $72 \%$ of the population presenting in these areas. When the $\mathrm{HSCl}$ was 0.59 and 0.75 , the cumulative percentages of population and GDP were almost equal to the cumulative percentage of land. In such cases, land was in a state of saturation, with approximately $10 \%$ of the population presenting in these areas. The distance between the population and GDP curves was smaller in areas with saturated land than in areas with unsaturated and supersaturated land, indicating a basic correlation between Liaoning's population-economy distribution and the suitability of its settlements.

The slope of the cumulative curve of population and GDP reflects the quantity of population and economy in the interval. The gradient was the largest when the $\mathrm{HSCl}$ was 0.5 , which indicates that land with a 0.5 suitability value had the densest population-economic distribution. As distance from 0.5 increases, the gradient becomes smaller and population distribution decreases. The normal distribution law shows that the population-GDP distribution in Liaoning was most distributed in places with the best human settlements and medium level. On the whole, land with an $\mathrm{HSCl}$ greater than 0.6 accounted for approximately $20 \%$ of the population and land with an $\mathrm{HSCl}$ less than 0.6 accounted for approximately $80 \%$ and was home to approximately $82 \%$ of the population. These results clarify that Liaoning's population-economy distribution and settlements were relatively coordinated, with land with high suitability for human settlements fully utilized.

\section{Discussion}

\subsection{Improve the evaluation index system}

In recent years, the research on the suitability of settlements has become more and more popular(Torretta et al., 2020; Xiao et al., 2018; Stroh et al., 2018). Based on suitability of settlements, this paper discusses the sustainable development and planning optimization of settlements(Liu et al., 2020; Rufino et al., 
2019; Ali and Ahmad, 2020). Suitability is the basis of the development and layout of settlements(Buruso, 2018; Fabrizio et al., 2019; Anand et al., 2020; Talukdar et al., 2020), which is closely related to the sustainable development of settlements(Wang et al., 2020; Megahed, 2020; Da Costa et al., 2018). Evaluation of the suitability of settlements is helpful to explore the possibility of solving problems of urban resources and population concentration, urban expansion(Xi et al., 2018), industrial transformation(Hu et al., 2020; Wang et al., b).

Human settlements is the result of human activities on the natural environment(Anand et al., 2020), including natural elements and humanistic elements(Ejigu and Tassie, 2020; Milanesi et al., 2015; Buruso, 2018; Megahed, 2020; Habibie et al., 2019). Natural elements are the basis of settlements layout development, and humanistic elements are also the pillar of settlements development(Hansen et al., 2020; Talukdar et al., 2020; Da Costa et al., 2018; Torretta et al., 2020). However, at present, most of the researches on the suitability settlements focus on the natural suitability of settlements(Hu et al., 2020), and consider the humanistic indicator of settlements(Zhang et al., 2018; Liu et al., 2020; Fuller et al., 2018; Omar and Raheem, 2016; Tezer et al., 2020; Cui et al., 2017; Yan et al., 2017). Therefore, based on the previous studies on natural suitability, this paper adds humanistic indicator to comprehensively evaluate suitability of sustainable development for settlements, to provide a new way for the study of suitability of settlements research perspective, enrich the evaluation index system. This is still a preliminary study, and there are some shortcomings. First, the indicators still need to be further improved, more comprehensive consideration should be given to natural elements and humanistic elements of settlements, such as natural disasters, natural resources and industrial factors. The evaluation indicators and the classification standards of suitability grade should be adjusted according to the research scale, different research areas. Secondly, the data of rating indicators are diversified, and the sources are remote sensing data and social statistics data, so the accuracy of remote sensing data and social statistics data have an impact on the research results. Thirdly, we should collect more abundant data to evaluate the temporal and spatial evolution characteristics suitability of settlements in a long time series, and predict the evolution trend suitability of settlements in the future.

\subsection{Suggestions on sustainable development of settlements}

Based on the natural and humanistic suitability elements of sustainable development for settlements in Liaoning Province, this paper quantitatively evaluates the comprehensive suitability of sustainable development for settlements (Fig. 8), and analyzes the spatial consistency between the comprehensive suitability index with population economic density, results show that $80 \%$ of the population economy in Liaoning Province is concentrated in the regions with better suitability of settlements, and the land use efficiency with higher comprehensive suitability.

By comparing the natural and humanistic suitability indices of cities, we can know that, Shenyang, Dalian, Yingkou and other cities have good natural and humanistic suitability, and the highest

Page $12 / 25$ 
comprehensive suitability index of settlements. The sustainable development of settlements should maintain the advantages of high suitability, pay attention to the optimization of urban green space environment, change the land use structure, provide land use efficiency, adapt to the current situation of urban population growth and economic agglomeration, change the urban industrial structure and development mode, adapt to the current situation of urban population growth and economic agglomeration, and realize the sustainable development of settlements. Due to the restriction of topography and hydrothermal climate, Huludao, Anshan, Fushun, Benxi and other cities have low natural suitability index, but good urban traffic accessibility, high air quality index and high humanistic suitability index. Affected by the good level of humanistic suitability, these cities have good suitability for sustainable development for settlements. Benxi, Chaoyang and other cities have the lowest natural and humanistic suitability index and comprehensive suitability index. The urban terrain undulation is large, which is not conducive to the urban layout and development and transportation infrastructure construction. The urban land use efficiency is low, and the transportation convenience is relatively poor. In order to improve the suitability of settlements, change the way of urban land use and improve the efficiency of building land use. To improve the coverage of urban green space, improve the urban ecological environment, and improve the comfort of humanistic settlements. Integrate urban resources, improve resource utilization efficiency,change the urban industrial structure, develop the tertiary industry and technology intensive innovation industry, and change the new economic growth mode. Improve the traffic construction, strengthen the logistics of population resources, and enhance the economic basis of urban sustainable development.

\section{Conclusion}

This study comprehensively evaluated the suitability of sustainable development for settlements in Liaoning Province by combining a natural element index of suitability and a humanistic element index of suitability. More specifically, to construct the natural element index, we combined four natural single element indexes, namely, the RDLS index, NDVI, hydrology index, and temperature and humidity index; meanwhile, to construct the humanistic element index, we combined four humanistic elements indexes, namely, the land cover index, NLI, LTAI, and AQI. We analyzed the spatial differentiation law of natural suitability, humanistic suitability, and comprehensive suitability of sustainable development for settlements in Liaoning to explore the correlation between the spatial distribution of population and GDP and the settlements' suitability. The results were as follows:

1) The spatial differentiation law of the natural suitability of Liaoning's settlements was affected by the fact that the land was characterized by a central plain and hilly terrain to the east and west; accordingly, the RDLS index was the lowest in the central region and relatively higher to the east and west. Meanwhile, the vegetation coverage conditions in the east were significantly better than those in the central and western regions, and the NDVI was the lowest in urban regions. Regarding temperature and humidity, the western region proved hotter and drier than the central and eastern regions, and thus the spatial distribution of the temperature and humidity index shows a gradual decrease from the west to the eastthese results were the opposite of those we uncovered regarding Liaoning's hydrology conditions. Overall, 
the natural suitability of Liaoning's settlements was higher in the central and coastal regions than in the eastern and western regions, and the vertical differentiation law extended from northeast to southwest, following the direction of the mountains. Notably, Shenyang, Dalian, and Yingkou demonstrated the highest natural suitability index,was 0.601 . while Chaoyang and Benxi demonstrated the lowest natural suitability index, was 0.182 .

2) Regarding the spatial differentiation law of the humanistic suitability of sustainable development for settlements in Liaoning, we found that both the land cover index and the NLI showed the spatial differentiation characteristics of higher central and coastal regions and lower eastern and western regions; the LTAI was generally high, and the spatial difference was relatively small, with Shenyang, Dalian, and Huludao as the center. The spatial distribution presented in a circular structure with multiple connected centers and gradually decreased from east to west. Meanwhile, the AQI, which is closely connected to urban development, was significantly better in the east and west than in the central region. Overall, the locations of the highest to lowest humanistic suitabilities were as follows: the middle, eastern, and western regions-Shenyang, Dalian, and Huludao-had the highest humanistic suitability index was 0.831 , and Chaoyang the lowest was 0.280 .

3) The spatial differentiation law of comprehensive suitability index of Liaoning's settlements revealed that the central and coastal regions had the highest comprehensive suitability, followed by the eastern region. The lowest comprehensive suitability index was in the west. Therefore, the comprehensive suitability index presented a vertical differentiation law from northeast to southwest, conforming to the terrain trend. Shenyang, Dalian, and Huludao had the highest comprehensive suitability index was 0.749 ,while Chaoyang, Benxi, and Fushun had the lowest was 0.170 .

4) The population and GDP densities of Liaoning were basically consistent with the spatial distribution of the comprehensive suitability index of its settlements; the correlation indexes between the comprehensive suitability index and the spatial distribution of population density and GDP density were 0.168 and 0.171 , respectively. The RDLS index and the NDVI were found to be negatively correlated with the spatial distributions of population and GDP densities; meanwhile, all indexes were positively correlated with these elements. We found that Liaoning's population-economy was most notably distributed in areas

with the best and medium level of human settlements. Therefore, the distribution of population-economy and settlement suitability in Liaoning proved relatively coordinated. We also found that land highly suitable for settlements has been fully utilized.

\section{Declarations}

Acknowledgements: This research study was supported by the National Natural Science Foundation of China (grant no.41471140, 41171137,41671158), the Natural Science Foundation of Liaoning Province(grant no.2020-BS-182).

Conflicts of Interest: The authors declare no conflict of interest. 


\section{References}

Ahamed, T., Noguchi, R. \& Muhsin, N., et al. (2020) Sustainable agricultural development: a micro-level GIS-based study on women's perceptions of environmental protection and entrepreneurship in Japan and Bangladesh. GeoJournal.

Alatawi, A.S., Gilbert, F. \& Reader, T. (2020) Modelling terrestrial reptile species richness, distributions and habitat suitability in Saudi Arabia. Journalof Arid Environments, 178, 104153.

Ali, S.A. \& Ahmad, A. (2020) Suitability analysis for municipal landfill site selection using fuzzy analytic hierarchy process and geospatial technique. Environmental Earth Sciences, 79(10).

Anand, A., Krishnan, P. \& Suryavanshi, A.S., et al. (2020) Identification of Suitable Aquaculture Sites Using Large-Scale Land Use and Land Cover Maps Factoring the Prevailing Regulatory Frameworks: A Case Study from India. Journal of the Indian Society of Remote Sensing.

Bathrellos, G.D., Gaki-Papanastassiou, K. \& Skilodimou, H.D., et al. (2013) Assessment of rural community and agricultural development using geomorphological-geological factors and GIS in the Trikala prefecture (Central Greece). Stochastic Environmental Researchand Risk Assessment, 27(2), 573-588.

Buruso, F.H. (2018) Habitat suitability analysis for hippopotamus (H. amphibious) using GIS and remote sensing in Lake Tana and its environs, Ethiopia. Environmental Systems Research, 6(1), 6.

Bikdeli, S. (2020) Redevelopment modeling for land suitability evaluation of the suburb brown-fields using fuzzy logic and GIS, northeastern Iran. Environment, Development and Sustainability, 22(7), 62136232.

Chavez-Rosales, S., Palka, D.L. \& Garrison, L.P., et al. (2019) Environmental predictors of habitat suitability and occurrence of cetaceans in the western North Atlantic Ocean. Scientific Reports, 9(1).

Cui, X., Wu, X. \& He, X., et al. (2018) Regional suitability of virtual water strategy: Evaluating with an integrated water-ecosystem-economy index. Journal of Cleaner Production, 199, 659-667.

Casarotto, A., Pelgrom, J. \& Stek, T.D. (2019) A systematic GIS-based analysis of settlement developments in the landscape of Venusia in the Hellenistic-Roman period. Archaeological and Anthropological Sciences, 11(2), 735-753.

Cui, Y., Xiao, X. \& Zhang, Y., et al. (2017) Temporal consistency between gross primary production and solar-induced chlorophyll fluorescence in the ten most populous megacity areas over years. Scientific Reports, 7(1).

Da Costa, S.M., Cordeiro, J.L.P. \& Rangel, E.F. (2018) Environmental suitability for Lutzomyia (Nyssomyia) whitmani (Diptera: Psychodidae: Phlebotominae) and the occurrence of American cutaneous leishmaniasis in Brazil. Parasites \& Vectors, 11(1), 155. 
Ejigu, D. \& Tassie, N. (2020) Present and future suitability of the Lake Tana Biosphere Reserve in Ethiopia for the Nile monitor (Varanus niloticus) using the MaxEnt model. Environmental Systems Research, 9(1).

Fabrizio, M., Di Febbraro, M. \& D Amico, M., et al. (2019) Habitat suitability vs landscape connectivity determining roadkill risk at a regional scale: a case study on European badger (Meles meles). European Journalof Wildlife Research, 65(1), 7.

Fuller, L., Shewring, M. \& Caryl, F.M. (2018) A novel method for targeting survey effort to identify new bat roosts using habitat suitability modelling. European Journalof Wildlife Research, 64(3), 31.

Ge, J., Zhao, Y. \& Luo, X., et al. (2020) Study on the suitability of green building technology for affordable housing: A case study on Zhejiang Province, China. Journal of Cleaner Production, 275, 122685.

Hou, K., Zhou, J. \& Li, X., et al. (2016) Study on GIS Visualization in Evaluation of the Human Living Environment in Shenyang-Dalian Urban Agglomeration. Scientifica, 1-10.

Hu, X., Gao, L. \& Ma, C., et al. (2020) Land use zoning of Weifang North Plain based on ecological function and geo-environmental suitability. Bulletin of Engineering Geology and the Environment, 79(5), 2697-2719.

Habibie, M.I., Noguchi, R. \& Shusuke, M., et al. (2019) Land suitability analysis for maize production in Indonesia using satellite remote sensing and GIS-based multicriteria decision support system. GeoJournal.

Hansen, M.F., Nawangsari, V.A. \& van Beest, F.M., et al. (2020) Habitat suitability analysis reveals high ecological flexibility in a "strict" forest primate. Frontiers in Zoology, 17(1).

Jiao, S., Gao, Q. \& Wei, C., et al. (2012) Ecological suitability evaluation for urban growth boundary in red soil hilly areas based on fuzzy theory. Journal of Central South University, 19(5), 1364-1369.

Jiao, S., Zhang, B.J. \& Han, Z.W. (2020) Spatial-Temporal Evolution of Land Transportation Accessibility and Economic Contact in Xiangxi Area in Recent 70 Years. Economic Geography, 40(6), 137-146.

Jin, X.X., Ye, S.L. \& Wu, X.Y., et al. (2016) A quality evaluation of human settlements in island cities: a comparison between Xiamen and Pingtan. Acta Ecologica Sinica, 36(12), 3678-3686.

Li, X.M. \& Jin, P.Y. (2012) Characteristics and Spatial-temporal Differences of Urban Human Settlement Environment in China. Scientia Geographica Sinica, 32(5), 521-529.

Li, C., Li, Z. \& Guan, L., et al. (2017) Measuring the Complexity of Chaotic Time Series by Fuzzy Entropy. Future Networks and Distributed Systems.

Li, X.M., Zhang, D.H. \& Tian, S.Z., et al. (2018) Spatial and Temporal Differences of Urban Residential Quarter Floor Area Ratio: A Case Study of Four Districts in Dalian. Scientia Geographica Sinica, 38(4), 
$531-538$.

Li, Z.Z. \& Zhen, F. (2019) Evaluation of urban life space quality based on multi-source data:a case study of Nanjing. HumanGeography, 34(6), 53-61.

Luo, J., Zhou, T. \& Du, P., et al. (2019) Spatial-temporal variations of natural suitability of human settlement environment in the Three Gorges Reservoir Area-A case study in Fengjie County, China. Frontiers of Earth Science, 13(1), 1-17.

Li, Y., Liu, C. \& Zhang, H., et al. (2011) Evaluation on the human settlements environment suitability in the Three Gorges Reservoir Area of Chongqing based on RS and GIS. Journal of Geographical Sciences, 21(2), 346-358.

Liu, Y., Deng, W. \& Peng, L. (2020) The coupling mechanism between the suitable space and rural settlements considering the effect of mountain hazards in the upper Minjiang River basin. Journal of Mountain Science, 17(11), 2774-2783.

Milanesi, P., Caniglia, R. \& Fabbri, E., et al. (2015) Non-invasive genetic sampling to predict wolf distribution and habitat suitability in the Northern Italian Apennines: implications for livestock depredation risk. European Journalof Wildlife Research, 61(5), 681-689.

Maimaiti, A., Wang, L.M. \& Zhang, J., et al. (2017) Environmental suitability evaluation for human settlements in Bosten Lake Basin. IOP conference series. Earth and environmental science, 57, 12008.

Megahed, H.A. (2020) GIS-based assessment of groundwater quality and suitability for drinking and irrigation purposes in the outlet and central parts of Wadi El-Assiuti, Assiut Governorate, Egypt. Bulletin of the National Research Centre, 44(1).

Mamat, A., Halik, Ü. and Rouzi, A. (2017) Spatial evaluation of environmental suitability for human settlements based on GIS: A case study in Kaidu River Basin, Northwest China. Fresenius Environmental Bulletin, 1-9.

Nouri, H., Mason, R.J. \& Moradi, N. (2017) Land suitability evaluation for changing spatial organization in Urmia County towards conservation of Urmia Lake. Applied Geography, 81, 1-12.

Omar, N.Q. \& Raheem, A.M. (2016) Determining the suitability trends for settlement based on multi criteria in Kirkuk, Iraq. Open Geospatial Data, Software and Standards, 1(1), 10.

Pourebrahim, S., Hadipour, M. \& Bin Mokhtar, M. (2011) Integration of spatial suitability analysis for land use planning in coastal areas; case of Kuala Langat District, Selangor, Malaysia. Landscape Urban Plan, 101(1), 84-97.

Pearson, C. (2020) Book review: Historical Maps and Classical Thoughts of Human Settlements in Chinese Cities. Urban Studies, 57(12), 2582-2585. 
Qiu, L., Pan, Y. \& Zhu, J., et al. (2019) Integrated analysis of urbanization-triggered land use change trajectory and implications for ecological land management: A case study in Fuyang, China. Scienceofthe Total Environment, 660, 209-217.

Rufino, F., Busico, G. \& Cuoco, E., et al. (2019) Evaluating the suitability of urban groundwater resources for drinking water and irrigation purposes: an integrated approach in the Agro-Aversano area of Southern Italy. Environmental Monitoringand Assessment, 191(12).

Sarı, F., Ceylan, D.A. \& Özcan, M.M., et al. (2020) A comparison of multicriteria decision analysis techniques for determining beekeeping suitability. Apidologie, 51(4), 481-498.

Shao, Q., Liu, X. \& Zhao, W. (2020) An alternative method for analyzing dimensional interactions of urban carrying capacity: Case study of Guangdong-Hong Kong-Macao Greater Bay Area. Journal of Environmental Management, 273, 111064.

Sun, H.H., Zhen, F. \& Luosang, Z.X. (2018) Study on the spatial characteristics of supply and demand of urban amenities based on network big data: a case study of central urban area of Nanjing. Human Geography, 33(6), 62-68.

Saatsaz, M., Monsef, I. \& Rahmani, M., et al. (2018) Site suitability evaluation of an old operating landfill using AHP and GIS techniques and integrated hydrogeological and geophysical surveys. Environmental Monitoringand Assessment, 190(3).

Talukdar, N.R., Choudhury, P. \& Ahmad, F., et al. (2020) Habitat suitability of the Asiatic elephant in the trans-boundary Patharia Hills Reserve Forest, northeast India. Modeling Earth Systems and Environment, 6(3), 1951-1961.

Torretta, E., Dondina, O. \& Delfoco, C., et al. (2020) First assessment of habitat suitability and connectivity for the golden jackal in north-eastern Italy. Mammalian Biology, 100(6), 631-643.

Tezer, A., Turkay, Z. \& Uzun, O., et al. (2020) Ecosystem services-based multi-criteria assessment for ecologically sensitive watershed management. Environment, Development and Sustainability, 22(3), 2431-2450.

Ustaoglu, E. \& Aydınoglu, A.C. (2020) Suitability evaluation of urban construction land in Pendik district of Istanbul, Turkey. Land Use Policy, 99, 104783.

Wang, J.W., Chow, W.T.L. \& Wang, Y. (2019) A global regression method for thermal sharpening of urban land surface temperatures from MODIS and Landsat. International Journalof Remote Sensing, 41(8), 2986-3009.

Wei, W., Shi, P. \& Zhou, J., et al. (2013) Environmental suitability evaluation for human settlements in an arid inland river basin: A case study of the Shiyang River Basin. Journal of Geographical Sciences, 23(2), 331-343. 
Weisong, M., Shaoqi, G. \& Stankovski, S., et al. (2019) WebGIS-based suitability evaluation system for Chinese table grape production. Computersand Electronics in Agriculture, 165, 104945.

Wei, Z.C., Zhen, f. \& Qin, X. (2020) Quality of residential environment of affordable housing estates in Guangzhou and its institutional explanations. Scientia Geographica Sinica, 40(1), 89-96.

Wang, Y., Zhu, Y. \& Yu, M., et al. (2020) Quantitative evaluation and spatial differentiation of ecoenvironmental livability in Zhejiang Province, China. Journal of Mountain Science, 17(6), 1491-1508.

Xiao, H., Cao, L. \& Wang, Y. (2019) Suitability Evaluation of Rural Human Settlements in Pengxi County Based on GIS. Iop Conference, 376(1),2019.

Xiao, C., Feng, Z. \& Li, P., et al. (2018) Evaluating the suitability of different terrains for sustaining human settlements according to the local elevation range in China using the ASTER GDEM. Journal of Mountain Science, 15(12), 2741-2751.

Xi, C., Qian, T. \& Chi, Y., et al. (2018) Relationship between settlements and topographical factors: An example from Sichuan Province, China. Journal of Mountain Science, 15(9), 2043-2054.

Yang, J., Guan, Y. \& Xia, J.C., et al. (2018) Spatiotemporal variation characteristics of green space ecosystem service value at urban fringes: A case study on Ganjingzi District in Dalian, China. Scienceofthe Total Environment, 639, 1453-1461.

Yang, J., Wang, Y. \& Xiu, C., et al. (2020) Optimizing local climate zones to mitigate urban heat island effect in human settlements. Journal of Cleaner Production, 275, 123767.

Yang, X. \& Zhang, W.Z. (2016) Combining natural and human elements to evaluate regional human settlements quality based on raster data: A case study in Beijing-Tianjin-Hebei region. Acta Geographica Sinica, 71(12), 2141-2154.

Yan, H., Liu, F. \& Liu, J., et al. (2017) Status of land use intensity in China and its impacts on land carrying capacity. Journal of Geographical Sciences, 27(4), 387-402.

Zheng, X., Zhong, D. \& He, Y., et al. (2019) Seasonality modeling of the distribution of Aedes albopictus in China based on climatic and environmental suitability. Infectious Diseases of Poverty, 8(1).

Zhang, Y., Xiao, X. \& Zhang, Y., et al. (2018) On the relationship between sub-daily instantaneous and daily total gross primary production: Implications for interpreting satellite-based SIF retrievals. Remote Sensingof Environment, 205, 276-289.

\section{Tables}

Due to technical limitations, Tables 1 and 2 are only available as a download in the supplemental files section 


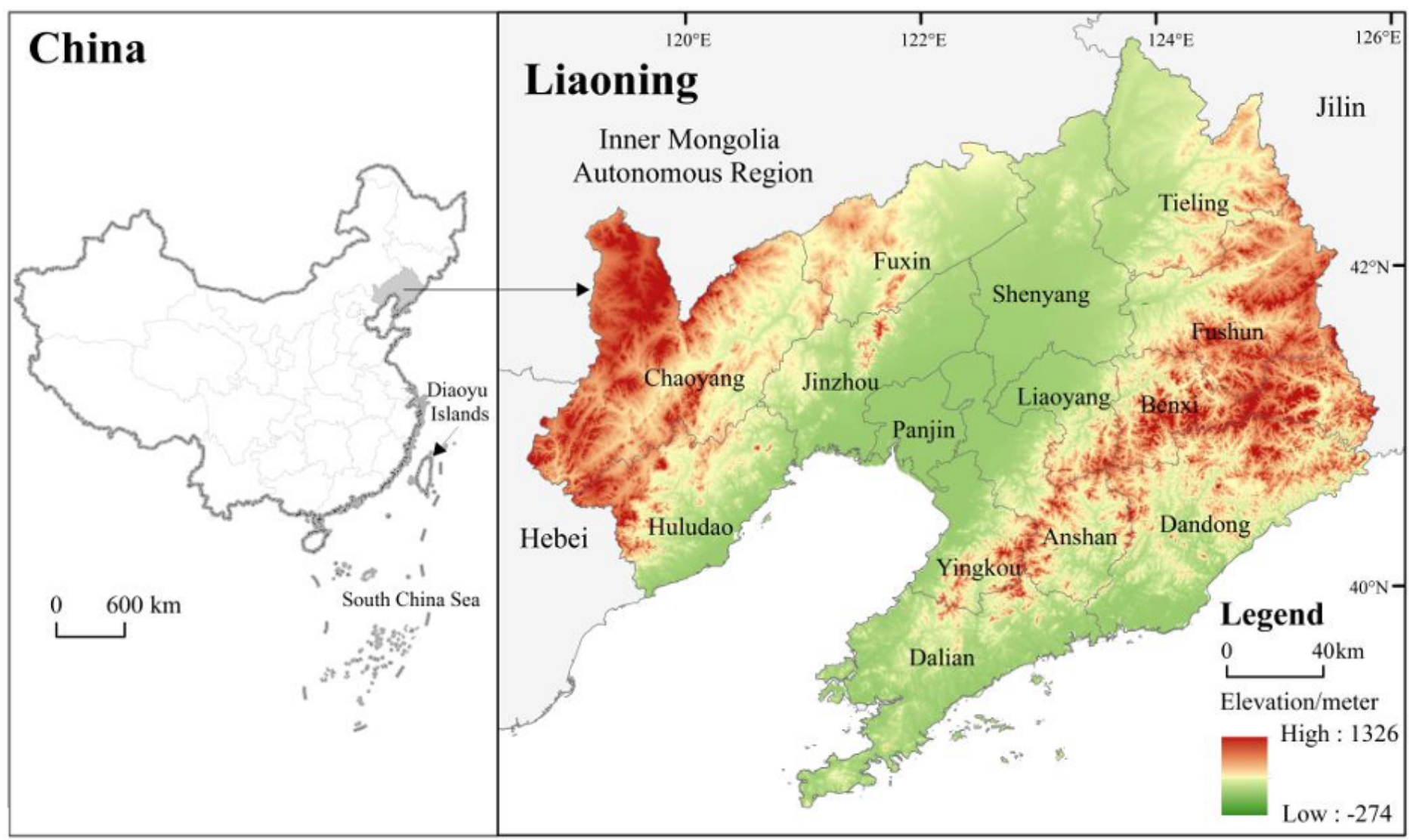

\section{Figure 1}

Location of study. Note: The designations employed and the presentation of the material on this map do not imply the expression of any opinion whatsoever on the part of Research Square concerning the legal status of any country, territory, city or area or of its authorities, or concerning the delimitation of its frontiers or boundaries. This map has been provided by the authors. 


Original data

\section{Figure 2}

\section{Technology road map}

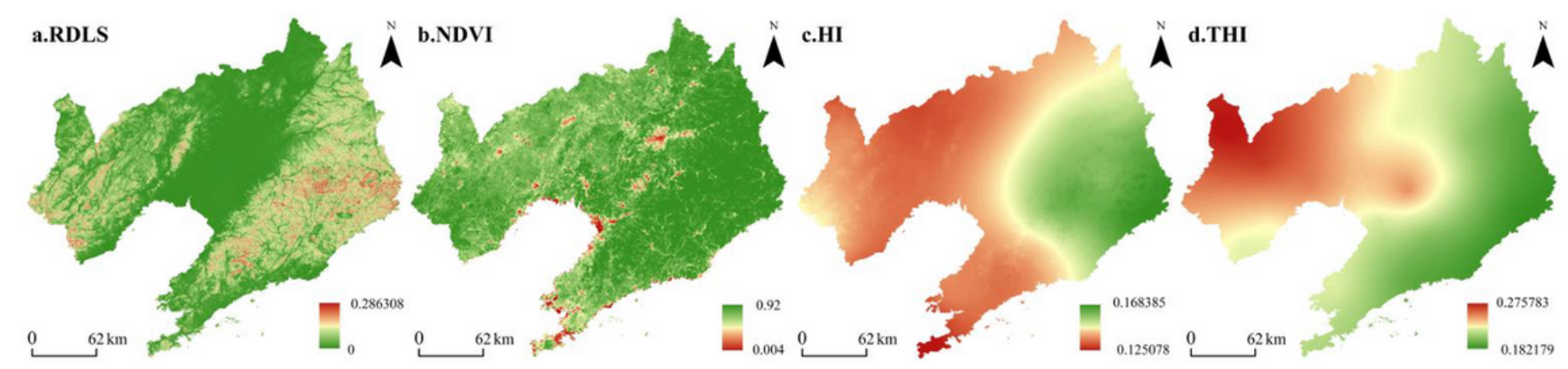

\section{Figure 3}

Spatial distribution of natural suitability single element indices. Note: The designations employed and the presentation of the material on this map do not imply the expression of any opinion whatsoever on the part of Research Square concerning the legal status of any country, territory, city or area or of its authorities, or concerning the delimitation of its frontiers or boundaries. This map has been provided by the authors. 


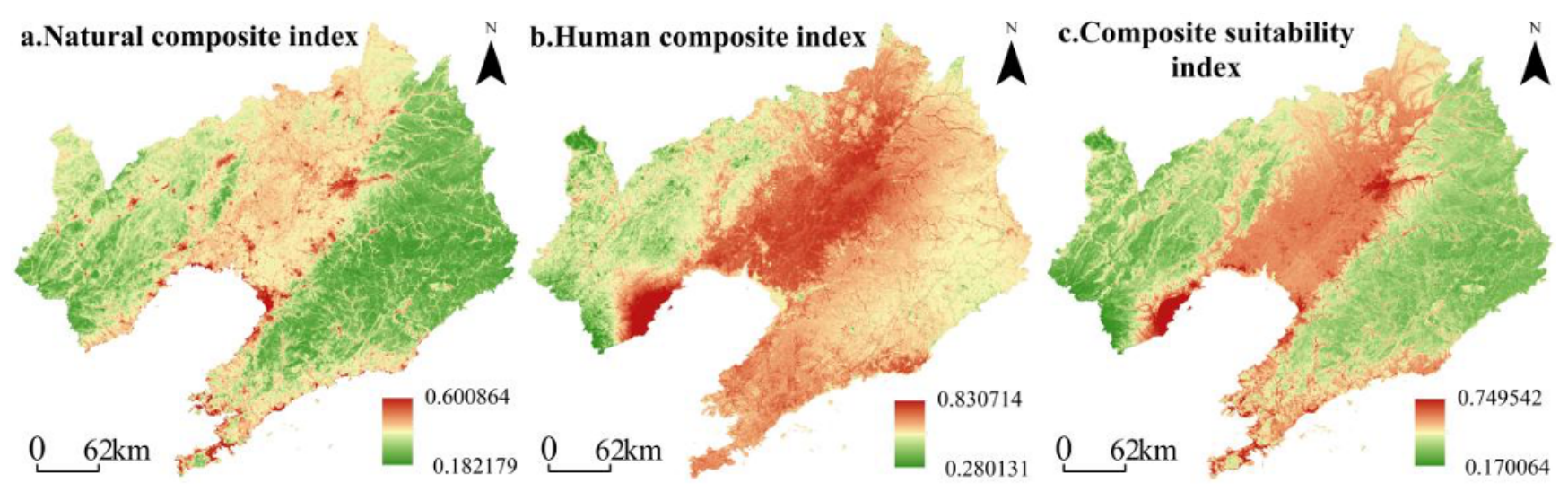

\section{Figure 4}

Spatial distribution of natural element composite index,humanistic element composite index, composite suitability index. Note: The designations employed and the presentation of the material on this map do not imply the expression of any opinion whatsoever on the part of Research Square concerning the legal status of any country, territory, city or area or of its authorities, or concerning the delimitation of its frontiers or boundaries. This map has been provided by the authors.

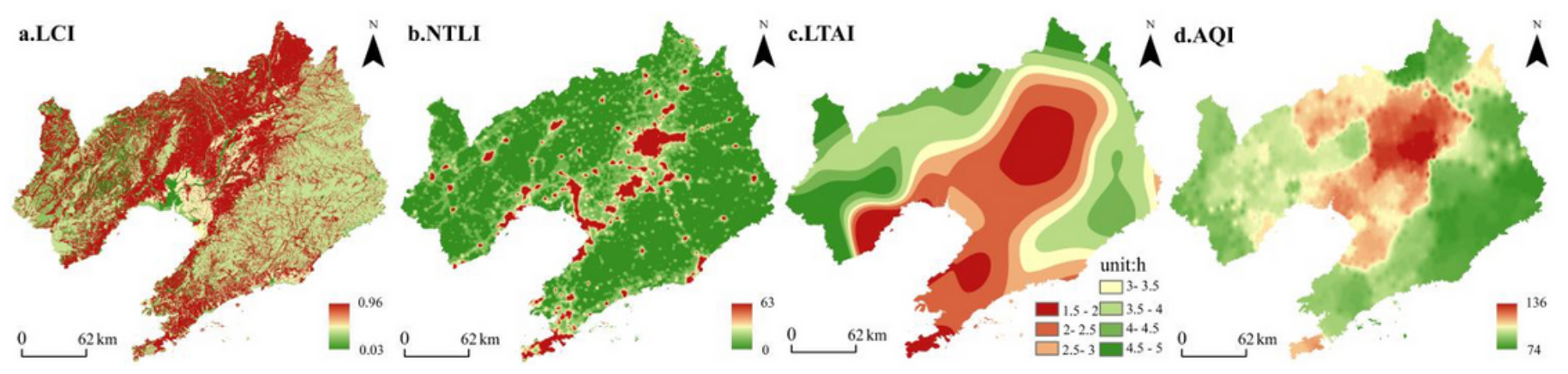

Figure 5

Spatial distribution of humanistic suitability single element indices. Note: The designations employed and the presentation of the material on this map do not imply the expression of any opinion whatsoever on the part of Research Square concerning the legal status of any country, territory, city or area or of its authorities, or concerning the delimitation of its frontiers or boundaries. This map has been provided by the authors. 


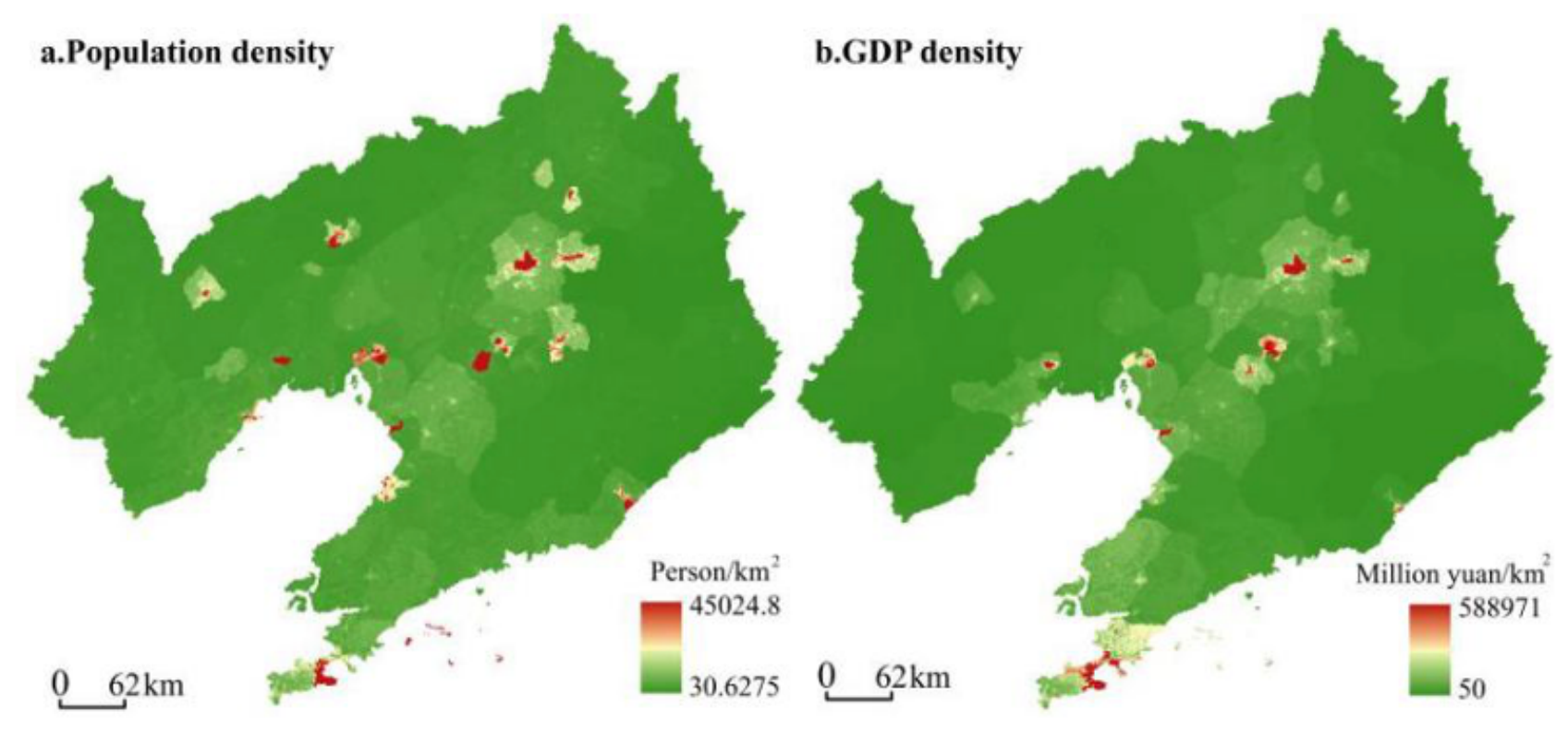

Figure 6

Spatial distribution of Population density and GDP density. Note: The designations employed and the presentation of the material on this map do not imply the expression of any opinion whatsoever on the part of Research Square concerning the legal status of any country, territory, city or area or of its authorities, or concerning the delimitation of its frontiers or boundaries. This map has been provided by the authors. 


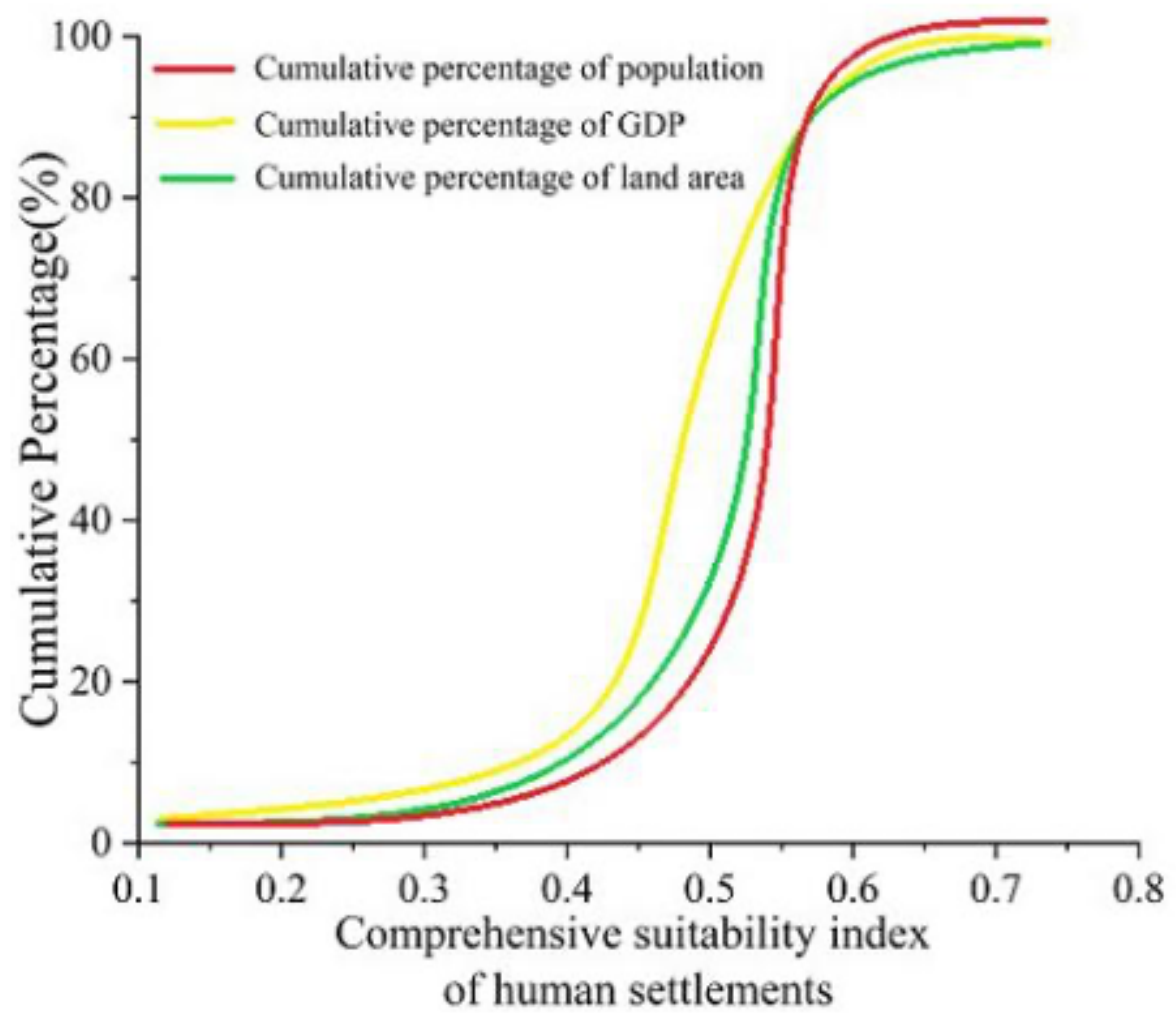

Figure 7

Land, population and GDP cumulative percentage curves 


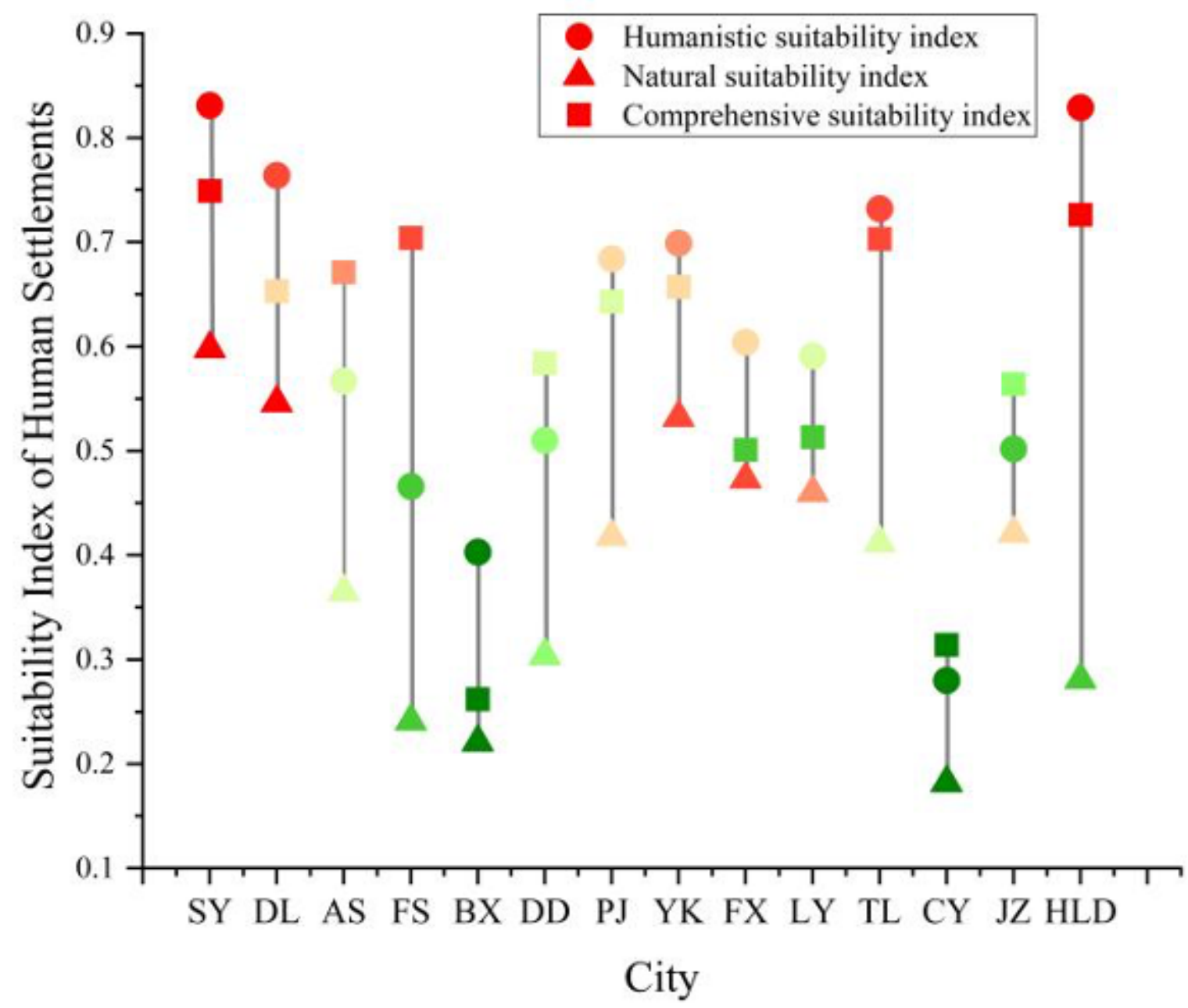

Figure 8

Suitability index of settlements of each city in Liaoning Province. Note: SY is Shenyang, DL is Dalian; AS is Anshan, FS is Fushun; BX is Benxi; DD is Dandong; PJ is Panjin; YK is Yingkou; FX is Fuxin; LY is Liaoyang; TL is Tieling; CY is Chaoyang; JZ is Jinzhou; HLD is Huludao.

\section{Supplementary Files}

This is a list of supplementary files associated with this preprint. Click to download.

- Tables12.docx 